\title{
MODERN TECHNOLOGY AS A SUSTAINABLE SOLUTION TO THE DROUGHT IN AFRICA: A CASE OF THE HORN OF AFRICA
}

\author{
*Kieran E. UCHEHARA \\ *Hasan Kalyoncu University, Turkey
}

\begin{abstract}
The paper provides an overview of drought conditions in the Horn Africa and suggests measures in order to combat the impact of drought in the region. The Horn of Africa covers numerous countries including Djibouti, Ethiopia, Kenya, Somalia, South Sudan, Uganda. Drought has severe adverse effects on sustainable development in the region. It causes agricultural production to fall, leading to food shortages and food insecurity, which in turn give rise to famine, water scarcity and loss of human life. The East Africa drought crisis is grave. It is a major concern for the continent, international community, and, the region, where a majority of a population relies on rainfall to grow food. Its management is an important element in the drive for sustainable development in the continent as whole and the region in particular. The need to address this, is intricately linked with the effort to tackle poverty and food insecurity in the region. Improved access to food is a sine qua non for sustained progress in poverty eradication. The paper suggests technology based innovation as an appropriate and sustainable strategy to tackle drought conditions in the easterly region of the African continent. The paper argues that inappropriate application of technologies are the primary reason behind drought as a long-standing issue in the region. Furthermore, it claims that responses to tackle drought conditions in the region, did not achieve the adoption of modern technologies and innovations. It concludes that an urgent action must be taken to halt the drought but any responses must also be forward-looking and seek to build long-term resilience. Securing lasting food security in the Horn requires attention to be paid to modern technology and innovation.
\end{abstract}

Keywords: Africa, the Horn of Africa, drought, technology

\section{INTRODUCTION}

To many, it is a dire contrast that, in the twenty first century-one heralded by great advances in technologies-that drought, famine and hunger are still persist in some parts of the world (Kaushik and Singh, 2004). The end of the Cold War brought about the expectation that the world's political and economic systems would change for the better, following the narrowing of ideological differences that had so polarized the world (Arnell, 2006). It was hoped that humanity could at last be better off as all would be able to benefit from a new era of technologies and innovation. To this date, however, this has not been the case and in contrast and on a daily basis, there is much news coverage of drought, famine, and poverty in various parts of the globe (Barrett, 2005). The impacts of drought and desertification are among the most costly events and processes in Africa. The widespread poverty, the fact that a large share of Africa's economies depend on climate-sensitive sectors mainly rain fed agriculture, poor infrastructure, heavy disease burdens, high dependence on and unsustainable exploitation of natural resources, and conflicts render the continent especially vulnerable to impacts of drought and desertification (Conceição, et al., 2011). The consequences are mostly borne by the poorest people and the Small Island Developing States (SIDS) (Ha-Joon, 2009). In the region, women and children in particular, bear the greatest burden when land resources are degraded and when drought sets in (Shaohua and Ravallion, 2010; Collier, 2008). As result of the frequent droughts and desertification, the Horn of Africa has continued to witness food insecurity including devastating famines, water scarcity, poor health, economic hardship, social and political unrest (Edwards, 2008). This paper aims to provide an overview of drought conditions in the Horn of Africa and it does this by 
Journal of Global Strategic Management | V. 7 | N. 1 | 2013-June | isma.info | 140-153 | DOI: 10.20460/JGSM.2013715680 analyzing the drought conditions in six countries in the region. Its objective is to serve the international community to formulate policies as 'directives toward action' in order to combat drought and its aftermaths in East Africa. The question the paper asks is: What are the international community's responses to combat drought conditions in the region? Interventions to the gravity of drought impacts in the region, are demonstrated below by analyzing drought conditions in six countries in the region such as Djibouti, Ethiopia, Kenya, Somalia, South Sudan and Uganda. The conclusion section summarizes the discussion.

\section{Definitions}

There is no universal definition of drought, but meteorologists monitor the extent and severity of drought in terms of rainfall deficiencies. A more in-depth definition of drought includes four subdefinitions; these are meteorological, hydrological, agricultural, and socio-economic drought. Agriculturalists, in turn, rate its impact on primary industries, hydrologists compare ground water levels, and sociologists define it in terms of social expectations and perceptions (Alley, 1984; Elodie, et. al., 2010; Ellis and Swift, 1988; Collins, 2002; Davidson, 1969).

For the purpose of this paper, we define drought as a 'prolonged, abnormally dry period when there is not enough water for users' ordinary and daily needs'. A drought in this sense is an extended period of months or years when a region notes a deficiency in its water supply. Generally, this occurs when that region receives consistently below average precipitation levels which can have a substantial impact on the ecosystem and agriculture of the affected region. Although droughts can persist for several years, even a short, intense drought can cause significant damage, and harm the local economy (Wilhite, 2000; Keddy, 2007). At a certain moment, depending on a combination of physical and social factors, a prolonged dry period becomes a drought (Henriques and Santos, 1999).

Although drought has several definitions, but the central element in these definitions is water deficit. In general, drought is defined as an extended period-a season, a year, or several years-of deficient rainfall relative to the statistical multi-year average for a region (Safra, 2002; Joireman, 1997; Dewar and Wallis, 1999). This deficiency results in water shortage for a given activity, group, or environmental sector. Periods of drought can have significant environmental, agricultural, health, economic, and social consequences (Dewar and Wallis, 1999). The effect varies according to the degree of the vulnerability in the affected region. For example, subsistence farmers are more likely to migrate during drought because they do not have any other alternative food sources. Areas with populations that depend on farming as a major food source are more vulnerable to drought-triggered famine (Keen, 1994).

Globally, drought is a normal, recurring feature of the climate in most parts of the world (Heddinghaus and Sabol, 1991; Şarlak, Kahya and Bég, 2009). Modern peoples can effectively mitigate much of the impact of drought through irrigation, crop rotation and Technologies (Jennifer and Naylor, 2011; Burney, et al., 2010). Yet, the failure to do so carries a grave human cost in today's world, exacerbated by ever increasing population densities. Lengthy periods of drought have long been a key trigger for mass migration, and have played a key role in a number of ongoing conflicts and other humanitarian crises in the Horn of Africa as well as in the Sahel region.

Different scholars have provided differing definitions for 'famine'. Amartya Sen defines famine as "unequal distribution of food supply." His argument is that famine is not a shortage of aggregate food supply, but the inability of individuals to afford available food (Keen, 1994). In this sense, a good harvest throughout a year does not guarantee that there will be no famine. In some instances, governments may manipulate food supplies for political reasons, using food as a weapon. Another definition for famine is drawn from a local perception in Western Sudan. Famine, according to De Waal, is "a disruption of life, involving hunger and destitution for sometimes, but not always death" (Edkins, 2000). In this sense, De Waal has tried to make a distinction between the European perception of famine, starvation to death, and the African view that believes famine involves hunger and destitution, but not necessarily death. Other scholars relate behavioral changes with famine. Edkins, for example, states that famine is "a socio-economic process that causes the accelerated destitution of the most vulnerable and marginal groups in society" (Edkins, 2000). Trying to bring all these ideas together, a working definition can be inferred as 'a phenomenon in which a large 
Journal of Global Strategic Management | V. 7 | N. 1 | 2013-June | isma.info | 140-153 | DOI: 10.20460/JGSM.2013715680 percentage of population is so under nourished that death by starvation becomes very common' (Edkins, 2000). Drought, mismanagement of food supplies, and policy failures are causes of famine. In many cases, these situations exist together, each reinforcing the others.

\section{Drought Conditions in the Horn of Africa}

Recurring droughts leading to desertification in the Horn of Africa have created grave ecological catastrophes, prompting massive food shortages that exist to this day (Darkoh, 2003). To the northwest of the Horn, the Darfur conflict in the neighboring Sudan, also affecting Chad, was fueled by decades of drought. Combined with desertification and overpopulation, draughts are among the main causes of Darfur-like conflicts (Lotta and Wallensteen, 2011), because the Arab Baggara nomads searching for water have to take their livestock further south, to land mainly occupied by nonArab farming peoples (Edwards, 2008). Generally, rainfall is related to the amount of water vapor in the atmosphere, combined with the upward moving of the air mass containing that water vapor (Dewar and Wallis, 1999). If either is reduced, the result is a drought. This can be triggered by an above average prevalence of high pressure systems, winds carrying continental, rather than oceanic air masses-that is, reduced water content-and ridges of high pressure areas form patterns which prevent or restrict the developing of thunderstorm activity or rainfall over one certain region.

A more viable long-term solution that can help drought in an essential way needs to be found. Merely responding to the emergency appeal for humanitarian assistance is not a long-lasting solution to drought. A solution to it has to do, for instance, with the application of modern technologies and innovations.

\section{COUNTRY OVERVIEWS:}

\section{Djibouti}

Although rainfall fluctuations and drought are intrinsic features of Djibouti's semi-arid climate, the current drought far exceeds normal variation. Insufficient rainfall since 2005-with less than $50 \%$ of the normal average recorded since September 2007-has had a direct and life-threatening impact upon the most vulnerable people of Djibouti, particularly pastoralists and rural dwellers (De Witt and Stankiewicz, 2006). Two-thirds of the country receive less than $10 \mathrm{~mm}$ of rain, according to Famine Early Warning Systems Network (FEWSNET), causing depletion of water reserves, deterioration of livestock health and milk production, massive loss of livestock, and the resulting destruction of livelihoods and sources of income (De Witt and Stankiewicz, 2006).

The drought has led rural households to migrate within their region or through neighboring regions and, principally, towards the capital, Djibouti city. Households that could not afford to migrate suffered a loss of 70 percent to 100 percent of their livestock. The number of cultivated plots dropped sharply in the last four years of the drought. Increased rural-urban migration has concentrated 70.6 percent of the population in urban areas, including 58.1 percent in the capital city (Joireman, 1997; Dewar and Wallis, 1999). Water shortages in Djibouti city are expected to become a serious issue. Urban food insecurity is rising due to high levels of unemployment and an increase of food prices. Unemployment in the capital stands at 60 percent and is at its worst during the summer months (JulySeptember). Currently food prices are 68 percent over the five-year average, aggravated by deteriorating terms of trade. The country's resistance to international food price fluctuations is weak as 90 percent of food products are imported (Joireman, 1997; Dewar and Wallis, 1999).

\section{Ethiopia}

In Ethiopia, the prolonged La Niña conditions have affected two consecutive rainy seasons, causing rapidly deteriorating food security in the drought-affected lowlands of southern and south-eastern Ethiopia, as well as in parts of the central and southern highlands that depend on short-cycle crops cultivated during the February-to-May rainy season. By July 2011, the number of people identified in the Government's revised Humanitarian Requirements Document (HRD) as requiring relief food assistance had increased by 47 percent, to 4.56 million. The largest increases were recorded in Oromia 178 percent and Southern Nations, Nationalities and People's Region (SNNPR) 187 percent (Joireman, 1997; Dewar and Wallis, 1999). 
Due to drought, the conditions in Kenya's northern and northeastern districts deteriorated further after a poor March-to-June rain season. The current drought comes against a backdrop of climate change and associated global warming set to intensify the severity, duration, and frequency of droughts. An analysis of the rainfall status by the Kenyan Meteorological Department for the last 60 years illustrates that the long rains have particularly been deficient in the last ten years (Joireman 1997; Dewar and Wallis, 1999). Recovery gains made after the 2009/2010 El Niño heavy rains have been eroded. Severe drought is a consequence of several years of rainfall failure occurring in consecutive rainfall seasons, a situation that has eroded communities' ability to cope with, and recover from, poor seasons (Yillia, Kreuzinger, Mathooko, 2008). This has worsened food insecurity and water shortages, led to increased conflict in pastoral areas, and increased the risk of human and livestock disease outbreaks (Elodie, et al., 2010; Davies, 2009).

\section{Somalia}

In this country, other most affected districts are in north northeast, where food insecurity reach crisis levels. Meanwhile, drought across the Horn of Africa has consequences. The 1.4 million people in Somali targeted for relief food assistance constitute approximately one-third of the region's population (Dewar and Wallis, 1999; Joireman, 1997). Nationwide, the areas most severely affected by drought include the pastoral districts of Wajir, Marsabit, Isiolo, northern Garissa, northern Tana River, Mandera, and Samburu; and the south-eastern districts of Kitui, Makueni, Mwingi, and Tharaka. The devastating drought impacts have forced thousands of Somalis into Kenya's overcrowded Dadaab camps (Kwasi, 2009; Hazell and Hess, 2010).

The total failure of the October-to-December rains in 2010 and low downfall of April-to-June rains in 2011 resulted in crop failure, reduced demand for labor, pasture and water shortages, weak and low well-being of the livestock, and animal mortality (Hazell and Hess, 2010; Nyakairu, 2011). The decline in cereal availability and ongoing trade restrictions have led to high local cereal prices causing livestock-to-cereal/wage-to-cereal terms of trade to deteriorate sharply, substantially reducing the purchasing power in all the populated regions.

In the lowlands of the Somali Region, Southern Oromia and Southern (SNNPR), the failure of the short October-to-December rains in 2010 was followed by poor rains from March to May 2011 (Hazell and Hess, 2010; Nyakairu, 2011). While some rains belatedly fell in parts of the droughtaffected region in May, the temporary relief they brought from severe water and pasture shortages is already being exhausted. Water trucking, which began in some areas as early as November 2010 and expanded to include all districts of the Somali region and most of the southern Oromia and southern SNNPR by late April, was resumed in the southernmost areas of Somali and Oromia in July as the drought-affected areas entered a new dry season. Water shortages in most areas re-emerge and grow more severe in the months leading up to the forthcoming rains in October 2011. Early and large scale migrations of pastoralist households and their livestock within Ethiopia and from other countries reduced productivity and resulted in high rates of livestock death. High inflation-up to 45 percent in June 2011 compared to the same month in 2010-and limited availability of food and other goods in some markets, particularly in the Somali region, exacerbated the situation (Hazell and Hess, 2010; Nyakairu, 2011). The conditions are particularly acute in parts of SNNPR that depend on the consumption of sweet potatoes as a bridging food since other root crop harvests failed completely.

\section{South Sudan}

Global acute malnutrition remains above the emergency thresholds in many parts of South Sudan. Continued food insecurity is linked to conflict, population displacement, low levels of food production, and rising food prices (Tilman and Schindler, 2009; Bryceson, 2006). The current progress of the rains is of concern as erratic rainfall and dry spells in some states are still a matter to worry about. If the current rainfall pattern continues, the production of staples (maize and sorghum) will be negatively affected, increasing the risk of food insecurity. Pastures could be depleted, forcing herders to migrate in search of water and pasture. The effects of drought in the Horn of Africa could 

be felt along the border areas of Jonglei state in the form of reduced commodity flows from neighbouring countries (DeGrassi, 2005).

\section{Uganda}

Many parts of Uganda are food-secure following the good aggregate cereal production in 2010 and the forecast favoring production in most of the country in 2011. However, pockets of chronic food insecurity exist, particularly in the north. An estimated 600000 people are moderately food insecure, mainly in Karamoja and Acholi subregions (Alain and Sadoulet, 2010a; Nyakairu, 2011). The main threats to food security in Uganda are outbreaks of animal diseases, natural disasters, and the continuing challenges of post-conflict recovery process. There has been some localized impact of the drought crisis in the Horn of Africa in eastern and northern Uganda with late rains delaying planting, which will likely delay harvests in Septemebr and lengthen the lean season (Xinshen, Hazell and Thurlow, 2010; Dorosh, et al., 2012; Douglas, et al., 2007). In addition, an outbreak of foot-andmouth disease in February ended up in the closure of livestock markets and disrupted livelihoods in Nakarpiripirit and Amudat districts (Xinshen, Hazell and Thurlow, 2010).

In the vast desert areas of Afar, Somalia, and Borena, the predicament of pastoralists and traders has been aggravated by the poor functioning infrastructure system. The evidence here reinforces the hypothesis that drought is more a question of accessibility than availability. Inadequate roads and transport structures to the sparsely-populated desert areas, lack of access to credit facility due to seasonal mobility, and lack of market information make the marketing and the export of cattle and cattle products and food distribution in times of crisis both time- consuming and expensive (Quentin and Zaman, 2010). Thus, pastoralists are still caught in a poverty trap and faced with highly vulnerable famine and food security problems.

The Horn of Africa has a long history of recurring drought problems (Maxon, 1994; Stock, 2004). On the surface, it appears that eratic weather conditions have repeatedly triggered large-scale cattle and crop failures for predominate subsistence farmers. Agricultural production is highly variable and vulnerable to climatic variations. Reports of poor rains, presumed to lead to drought, are followed by graphic pictures of famine problems (Maxon, 1994; Stock, 2004). However, to portray ecological factors as the sole cause of the region's recurring predicament is to vastly oversimplify the situation. Poor infrastructure, misguided policy options, weak market systems, and seasonal migration patterns contribute to the ever-increasing drought problems in the region (Braun, 2009). Although drought is a natural disaster caused by a combination of driving forces, such as geographic location or inadequate rainfall over farm lands but the problem in the Horn of Africa is the conversion of dry, fragile, forested areas into crop land and pastures. The section below reviews international responses in combating desertification and mitigating impacts of drought in the region. Specifically addressed in this review is progress made at regional and global levels.

\section{Various Efforts and Responses}

One response to the problem of drought and famine was the Intergovernmental Authority on Development (IGAD). IGAD as a regional grouping of the Horn-Eastern African Countries of Djibouti, Eritrea, Ethiopia, Kenya, Somalia, Sudan, and Uganda (Elagib, 2009; Schreck and Semazzi, 2004).

The group has its head office in Djibouti and was established in 1986 by the heads of the member states with a narrow mandate to address droughts and other natural disasters that caused widespread famine in the region. Initially, as a result of its limited role and unfocused program along with organizational defects, IGAD failed to deal with drought and its related issues (Huber, 2008; Hunt, 2005). At that point, it became apparent that establishing an organization that could truly address the conflicts of the region was very vital.

In 1995 the heads of member States and governments decided to rejuvenate the organization into a regional political, economic, security, trade, and development entity (Braun, et al., 2009; UNHRC, 2005; Zehir, 2005). At a regional summit in 1996, council ministers endorsed a plan to enhance regional cooperation in the areas of conflict prevention, management and resolution, humanitarian affairs, food security, environmental protection, and economic cooperation and integration. Since 
Journal of Global Strategic Management | V. 7 | N. 1 | 2013-June | isma.info | 140-153 | DOI: 10.20460/JGSM.2013715680 2004, IGAD in its new form has been developing projects that target pastoral communities of Southwestern Ethiopia, Northwestern Kenya, southeastern Sudan, and North Eastern Uganda named the Karamoja Cluster (Braun, et al., 2009).

Drought, famine, and poverty are interlinked. None of the problems can be solved without addressing the others. The three aspects of drought response include:

(a) The first is to develop a strong early warning system for drought and famine is crucial. It should be adopted at local, national, and regional levels (Birch, 2006).

(b) The second is that states should strength cooperation among neighboring countries to combat drought and prevent famine. Furthermore, building networks and collaboration with various actors in the area helps to tackle problems of drought and famine. For instance, the United Nations Convention to combat famine has recommended research on "drought and famine, identifying causal factors both natural and human, addressing specific needs of local populations and enhancing local knowledge, skills, and know how." This is an important area of collaboration (Delworth, Findell and Knutson, 2005; UNHRC, 2005).

(c) The third is to build the capacity and preparation of traditional mechanisms for combating drought is a third key factor. Some of the traditional mechanisms are collecting/harvesting rainwater in man-made ponds, diversifying grazing lands, and planting trees such as cassava that adopt to dry climates. In addition, strengthening and empowering traditional conflict resolving mechanism contributes to building relationship among and across communities, which diminishes the frequency and intensity of armed conflict, and encourages cooperative solutions to other problems-for instance, drought and famine (FAO, 2007; UNHRC, 2005) .

However, the aim of IGAD in Eastern Africa when it was created in 1986, under a different name and in the wake of the deadly 1984 famine, was to help the Horn of Africa nations to anticipate and plan for the recurrent droughts that affect the region. Not all countries, however, have been able to implement its strategies effectively. At the point of its departure, IGAD only served as a forum for the states to discuss issues related to drought, and no state eversince has dared to raise the question of resolving conflicts or differences (Touval, 1997; Lewis, 1965).

In 2008, when the global food prices skyrocketed, famine swept across Ethiopia, threatening more than 14 million people in the Horn of Africa. Oxfam America, with support from the Bill and Melinda Gates Foundation, organized a two-step response to the crisis (Prasad and Staggenborg, 2008). The first focused on 225,000 farmers in Ethiopia most at-risk, and got them what they needed immediately-food. The second step was to organize cash-for-work projects that built dams, rehabilitated springs, and constructed roads, thereby helping the people of the Horn to strengthen their small farms and improve their resilience to future droughts (Prasad and Staggenborg, 2008).

There were other establishments that warned of the upcoming catastrophes. As evidence of a looming disaster in the region emerged in 2008, projections of the build-up of persistent drought were made by a number of respected institutions, such as the United States National Oceanic and Atmospheric Administration. It signalled in November 2008 that rainfall anomaly maps showed significant deficits in southern Somalia and southern Kenya (Braun, 1999; Chakrabarti, Srivastava and Shakya, 2009). This pattern, despite heavy rain during the autumn of 2009, was confirmed by the Famine Early Warning Systems Network, World Meteorological Organization and the European Community-funded Somali-based Food Security and Nutrition Analysis Unit, with the latter noting in February 2009 an "ongoing and sustained humanitarian crisis in Somalia", with 43 percent of the total population of the country, or around 3.2 million people, in need of emergency livelihood and life-saving assistance. Other projects-including those supported by the United States' 'Feed the Future' program, the Global Agriculture and Food Security Program, and organizations such as the Alliance for a Green Revolution in Africa-are finding new ways to bolster the productivity of small farmers across the developing world (Kaushik, 2004 and Singh, 2004).

At a time of intense debate over budgets, people around the world must remember that these kinds of investments not only save lives, improve livelihoods, and promote stability, but also save money in the long-run. Estimates show that emergency relief in famines costs seven times as much as preventing them. That is why it is more important than ever for the international community and the 
Journal of Global Strategic Management | V. 7 | N. 1 | 2013-June | isma.info | 140-153 | D0I: 10.20460/JGSM.2013715680

African governments to continue to support programs that provide small farmers with access to quality seeds and tools as well as reliable markets necessary to become self-sufficient. It is up to them to make sure this horrible famine would not continue into the future. To once-and-for-all break this cycle of drought-led famine requires a strategic vision and action that far outstrips the ostensibly good intentions of governments in the region and the international community. Yet, there are actions that can mitigate future crises which, in part, evolve around the ways socieities-driven by politicians-make use of science and technology.

\section{Inadequate Governance Capacity}

The responsive capacity of the regional governments to drought is low (Government of Kenya, 2004; Özşahin and Zehir, 2011). Many simply do not know what action to take and, therefore, lack longterm strategic vision for the region. Already all kinds of initiatives and projects have been, or are being explored, in order to tackle drought threats. Some of them do not work, while others do. However, changing the trends and moving towards a Horn of Africa that is more ecologically, socially, and economically sustainable is not easy-nor is it, yet, impossible. Together, many enthusiastic individuals in various private sectors, governmental, non-governmental, academic, and donor organizations can make a difference-each in their own specific ways and fields of activity.

The regional governments, by means of strong collaboration with international agencies as well as regional and non-governmental organizations should build on appropriate and sustainable strategies to tackle drought and related problems in the easterly region of the African continent that is characterized by intense poverty and food insecurity (Keen, 1994). Climate-smart agriculture, including scaled-up research on drought-resistant seeds and cross-border strategies for drought-risk reduction are essential over the medium and prolonged periods of planning; whereas, in the longer term, it is important for the countries in the Horn of Africa to prepare for recurring droughts that climate change will bring about-then, obviously with more intensity.

At this moment, heads of the states in the region possess an unprecedented opportunity to improve the lives of people by adopting practical approaches to meeting the drought-related mishaps. They have to identify the interventions and policy measures needed to achieve this goal. Let this not be disregarded that drought is a national disaster which can, indeed, be resolved through technology-based innovation, in a form that applies knowledge in development; the task force on science, technology, and innovation underscores the critical importance of knowledge and innovation for development in every country. Technological innovation and its associated institutional adjustments underpin longterm growth, and must be at the center of the regional future strategy to combat drought conditions. Innovation proposes concrete and practical steps that governments and international agencies can take to bring science, technology, and innovation to bear on development in the Horn of Africa. This can play a fundamental part in reforming drylands and reversing drought. Technology-based innovation is the long-term solution to the intervention in the Horn of Africa, as the system would monitor rainfall in the region. The regional governments' support of new technology is an important element of the innovation. In this sense, the past regional initiatives in tackling challenges of food security and climate change in the region did not have long-term strategic visions for the region (Food and Agricultural Organization, 2007; Held, et al., 2005). That is, the mechanisms for identifying the technologies which would benefit the entire region, does not currently exist.

One of the approaches by which the regional governments and their partners can apply to resolve drought conditions, such as food security and sustainable livelihoods in the region, is through the application of technological innovation that would act as the bridge between research and new ideas. Furthermore, a close working with the international community is crucial to overall success in the region-in brief, a domestic application of technology along with and international sense of collaboration to coordinate related and required measures.

The priority should be kept in mind that agriculturalists, pastoralists, and urban dwellers are in for difficult times. To become of a more awakening nature, these warnings have to be seen within the broader context of the origins of the crisis, as they are caught up in an array of other issues.

There are at least three problems facing those in power when it comes to using the available science. The first is that there was and is no systematic and consistent approach to bringing sciences into 
Journal of Global Strategic Management | V. 7 | N. 1 | 2013-June | isma.info | 140-153 | DOI: 10.20460/JGSM.2013715680 policy-making. In part, this is to do with the ways that science is all too often used to confirm the opinions of those in power rather than to guide them in adifferent direction. It also has to do with the uncertainties that frequently permeate how findings are presented, and the fact that scientific advice has to be sieved through the political, administrative and operational realities of those receiving it. The second is that the scientific information being applied has to be made more contextualized. For example, 'patterns of drought impact' alone does not provide any sufficient and precise information to identify differentiated effects upon populations, cattle, and agriculture. In the case of the present crisis, a combination of satellite remote-sensing and mobile technologies that can verify and differentiate impacts are available, yet they are not coordinated and integrated sufficiently well. Finally, there is a more fundamental issue that the Horn of Africa drought illuminates. Governments in the region and the international community have to begin to prioritise drought related vulnerabilities. To date, there has rarely been any coherent action, except when a crisis is imminent. There is no overarching framework or strategy that reflects a commitment to prevent and prepare for such events. Such a significant gap offers little incentive for a systematic and consistent dialogue between scientists and politicians, and little incentive for the two to learn how to engage.

Notes

1. The Horn of African region is currently under severe drought conditions, mainly in the drylands; located in Djibouti, Ethiopia, Kenya, Somalia, South Sudan and Uganda. This drought has come at the backdrop of the climate change associated with global warming and whose projections indicate occurence of more frequent and extreme climate events.

2. Many interventions aimed at improving dryland management did not achieve the adoption of new Technologies (Food and Agricultural Organization, 2007; Held, et al., 2005). Causes for low adoption include the lack of community participation in technology development, dissemination of inappropriate and expensive technologies and the indiscriminate use of direct incentives, leading to abandonment of the promoted technologies after termination of certain project based intervention. Therefore, the past interventions to improve drought conditions in the region often focused on inappropriate Technologies (Chizuni, 1994).

3. The term 'livelihood' comprises of the capabilities, assets (including both material and social resources) and activities required for a means of living. It is sustainable when it can cope with and recover from stresses and shocks and maintain or enhance its capabilities and assets. Livelihood approach inculcates a better understanding of the multi-dimensions of poverty and the factors that influence livelihoods. It helps in devising a support for poor people that builds on their strengths and livelihoods strategies and provides them with opportunities to escape from depravity. People are placed at the centre of development at various levels (micro-meso-macro). This provides an ample scope for working together with partners in a dynamic way.

4. While severe drought has undoubtedly led to the huge scale of the disaster, this crisis has been caused by people and policies, as much as by weather patterns (Chizuni, 1994). An adequate response to the current crisis must not only meet urgent humanitarian needs, but also address these underlying problems.

5. Food security and climate change are critical concerns facing this region and the world as a whole (Gray, 2000). There is a need to lay emphasis on a regional approach since whatever bedevils an individual nation affects the entire region. The member states must come up with proacticve and decisive action plans to deal with effects of climate change and attain food security for the East African region. They must commit themselves to regional initiatives to tackle drought conditions. Urgent action is required at regional, continental and global levels if today's food crisis is not to be a grim foretaste of future hunger and suffering.

6. Due to climate change which has caused erratic weather patterns, the region is now experiencing low agricultural production. It has continued to experience frequent droughts causing a recurrent problem of food shortages. There should be willingness and commitment by the respective governments in addressing the twin issues of food security and climate change so as to ensure the East African region meets the demands of food for its population. The leaders from the Horn of Africa 
Journal of Global Strategic Management | V. 7 | N. 1 | 2013-June | isma.info | 140-153 | DOI: 10.20460/JGSM.2013715680 region and the international community must assure of the government's commitment and desire to developed the drylands through new technologies.

7. Structured government support is an important element of the innovation system. It can facilitate the development of new technologies, help establish them in the market and encourage their adoption, drive economic growth and deliver other spillover benefits, such as the development of new skills.

8. In terms of government commitments, regional governments must be assisted to mainstream programmes and policies to adapt to climate change into national and sectoral development plans. Commitment to preparing agricultural development strategies for growth is an important step, but these strategies and associated investment plans must be implemented swiftly through substantial increases in public and private national and international investment. Governments should also work with subregional centres of excellences, national platforms and relevant national institutions to establish or strengthen existing systems and networks for drought monitoring, early warning and drought impact assessment (Mwaura, Baechler, and Kiplagat, 2003). In particular, there is a need to encourage the establishment of multidisciplinary institutional mechanisms in countries to support effective disaster risk reduction implementation, involving ministries of environment and of finance and planning. Another way is to work at the international level with the donor community to deal with the contentious issue of the externalization of disaster response and its separation from mainstream development priorities by ensuring strategic links between the two.

9. There is a need to develop and strengthen systems for monitoring, early warning and adaptation to drought and desertification (Mwaura, Baechler, and Kiplagat, 2003). A drought early warning system is designed to identify climate and water supply trends and thus to detect the emergence or probability of occurrence and the likely severity of drought. Effective systems must integrate precipitation and other climatic parameters with water information, such as streamflow, snowpack, groundwater levels, reservoir and lake levels, and soil moisture, into a comprehensive assessment of current and future drought and water supply conditions (Jury, 2007). This information can reduce impacts if delivered to decision makers in a timely and appropriate format and if mitigation measures and preparedness plans are in place. Owing to the frequent occurrence of drought and the profound impacts associated with it in the Horn, governments should pay more attention to the development of national strategies or policies to reduce its economic, social and environmental consequences (Kwasi, 2009). A critical component of any strategy is a comprehensive drought monitoring system that can provide early warning of the onset and end of drought, determine its severity and deliver that information to a broad client base in many climate-sensitive and water-sensitive sectors in a timely manner. With this information, the impacts of drought can be reduced or avoided in many cases.

\section{CONCLUSION}

Drought is a natural dissersta that is caused by a combination of driving forces, such as drylands and inadequate rainfall over agricultural lands. The population of the Horn of Africa, relies on rainfall to grow its food. However, rainfall in most of the countries in the region is low, unevenly distributed, highly variable and therefore unreliable. As the region has limited water resources, the scale and duration of rainfall is the main climatic factor determining land productivity. Excessive drought periods do not only have a negative direct impact on land productivity (impacting croplands and grazing areas), but have also stimulated further land deterioration through desiccation processes, causing shrinkage and cracking of the soil. It therefore negatively impacts food security both directly and indirectly. A comparison between food security conditions and ecological conditions in the region, shows a remarkable correlation between food insecurity and aridity. For instance, in many of the desert, arid and semi-arid steppe regions of Ethiopia, Somalia, Djibouti, Kenya and Uganda, food security is highly and extremely insecure. This indicates the importance of drought in explaining food insecurity, famine and poverty. Another issue is that there have always been cycles of drought and flooding in the region. Hence, the population of the region has always lived with an unstable environment, and has therefore not been able to develop specific coping strategies.

The various international efforts and responses to combat drought conditions in the region focused on only a few aspects and in an isolated manner without applying integrated approaches. A range of 
Journal of Global Strategic Management | V. 7 | N. 1 | 2013-June | isma.info | 140-153 | DOI: 10.20460/JGSM.2013715680

technological options is available as solutions to the problems faced by the countries in the region. The lack of introducing modern technologies in the region shows that they are either too sophisticated or costly for them to fund.

This paper argues that international responses to drought conditions in East Africa should be focused on long lasting solution to tackle the worsing crisis. There is a need for the international community, African Development Bank, African Union, alongside African nations and private individuals, to provide technological options and innovations in the form of aid to help relieve the region from its worst drought conditions. Continued, large-scale, multisectoral response is critical to prevent future drought and to support livelihoods, especially for poor agropastoral households. Their support must be provided to ensure that they are able not only to rebuild the livelihoods of the people in a short term, but ensure that these livelihoods are sustainable, more resilient and diversified in the longer term. Addressing drought in the region requires a multifaceted and multicultural long-term approach. This paper concludes that modern technologies and innovations are long-lasting solution to drought in the region as the systems can monitor drought and rainfall, help irrigation, water control and consumption in a more efficient way. 


\section{REFERENCES}

Alain, De Janvry and Sadoulet, Elisabeth. (2010a). "Agriculture for Development in Africa: Businessas-Usual or New Departures?” Journal of African Economics, Vol. 19, Issue 2, ii7-ii39.

Alley, W.M. (1984). “The Palmer Drought Severity Index: limitations and Assumptions.” Journal of Climate and Applied Meteorology, Vol. 23, 1100-1109.

Arnell, N.W. (2006). "Global Impacts of Abrupt Climate Change: An Initial Assessment.” Working Paper 99, 450-460.

Barrett, Christopher B. (2005). "Rural Poverty Dynamics: Development Policy Implications." Agricultural Economics, Vol. 32, Issue 1, 45-60.

Birch, Isobel. (2006). "Political Integration: From Above or from Below? A Perspective from Pastoralist Areas of East Africa" Unpublished MSc Dissertation, School of Oriental and African Studies (SOAS), London.

Braun, Joachim, von, Tesfaye Webb, Teklu and Patrick. (1999). Famine in Africa: Causes, Responses and Prevention. Baltimore, MD: The John Hopkins University Press, p. 18.

Braun, Joachim, Von. (2009). "Addressing the Food Crisis: Governance, Market Functioning, and Investment in Public Goods.” Food Security. Vol. 1, Issue 1, 9-15.

Bryceson, Deborah Fahy. (2006). "Fragile Cities: Fundamentals of Urban Life in East and Southern Africa." in: African Urban Economies: Viability, Vitality or Vitiation?, (ed.). Deborah Fahy Bryceson and Deborah Potts. London: Palgrave Macmillan. Insurance in Developing Economies." Journal of Public Economics, Vol. 90, Issue 12, 2351-56.

Burney, A. Jennifer and Rosamond, L. Naylor. (2011). "Smallholder Irrigation as a Poverty Alleviation Tool in Sub-Saharan Africa.” World Development, Vol. 40 Issue1, 110-23.

Burney, et al. (2010). "Solar-Powered Drip Irrigation Enhances Food Security in the Sudano-Sahel." Proceedings of the National Academy of Sciences, Vol. 107, Issue 5, 1848-53.

Chakrabarti, D., Srivastava, S. and Shakya, B. (2009). "Indigenous Knowledge of the Vulnerable Communities Living in Drought Prone Areas of Rajasthan, India", in: Indigenous Knowledge for Disaster Risk Reduction in South Asia. New Delhi: SAARC Disaster Management Centre, 49-79.

Chizuni, J. M. (1994). "Food Policies and Food Security in Zambia." Nordic Journal of African Studies, Vol. 3, Issue 1, 46-51.

Mwaura, Ciru, Baechler, Gunther and Kiplagat, Bethuell, "Background to Conflicts in the IGAD Region," in: Early Warning and Conflict Management in the Horn of Africa, (ed.). Ciru Mwaura and Susanne Schmeidl, Lawrenceville, NJ: Red Sea, 2003, p. 34.

Collier, Paul. (2008). “The Politics of Hunger: How Illusion and Greed Fan the Food Crisis.” Foreign Affairs, Vol. 87, Issue 6, 67-79.

Collins, R. (2002). “More than a Pipe Dream?” in: Water and Wastewater, Vol. 13, Issue 9.

Conceição, et al. (2011). "Food Security and Human Development in Africa: Strategic Considerations and Directions for Further Research.” African Development Review, Vol. 23, Issue 2, 237-46.

Darkoh, M. B. K. (2003). "Regional Perspectives on Agriculture and Biodiversity in the Dry Lands of Africa.” Journal of Arid Environments, Vol. 54, Issue 2, June 2003, pp. 261-279.

Davidson, B. (1969). Australia Wet or Dry: The Physical and Economic Limits to the Expansion of Irrigation. Melbourne University Press, 1969, 5.

Davies, D. (2009), "Somali Pirates Increase the Stakes.” Africa prospects, October 2009, pp. 12-15.

De Wit, Maarten and Stankiewicz, Jacek. (2006). "Changes in Surface Water Supply across African with Predicted Climate Change.” Science, Vol. 311, Issue 5769, 1917-21. 
Journal of Global Strategic Management | V. 7 | N. 1 | 2013-June | isma.info | 140-153 | D0I: 10.20460/JGSM.2013715680 DeGrassi, Aaron. (2005). "Transport, Poverty and Agrarian Change in Africa: Models, Mechanisms and New Ways Forward." Institute for Development Studies Bulletin, Vol. 36, Issue 2, 52-57.

Delworth, T. L., J. Lu., Findell, K.. and Knutson, T. R. (2005). "Simulation of Sahel Drought in the 20th and 21st Centuries. Proc. Natl. Acad. Sci. USA, 102, 17 891-17 896, doi:10.1073/pnas.0509057102.

Dewar, Robert, E. and Wallis, James, R. (1999). "Geographical Patterning in Interannual Rainfall Variability in the Tropics and Near Tropics: An L-Moments Approach.” Journal of Climate. Vol. 12, Issue $12,3457-3466$.

Dorosh, et al. (2012). "Road Connectivity, Population, and Crop Production in Sub-Saharan Africa." Agricultural Economics, Vol. 43, Issue 1, 89-103.

Douglas, et al. (2007). "Policy East Africa”. Merriam-Webster's Geographical Dictionary, 3rd (ed.). 2001. Springfield, MA: Merriam-Webster, Inc.; p. 339.

Dracup, J. A., Lee K. S., and Paulson, E. G. Jr. (1980). “On the Definition of Droughts.” Wat. Resour. Res. Vol. 16, Issue 2, 297-302.

Edkins, Jenny. (2000). "Whose Hunger?: Concepts of Famine, Practices of Aid." Minneapolis: University of Minnesota Press, p. 20.

Edwards, S. (2008). "Social breakdown in Darfur”, Forced Migration Review. Vol. 31, October 2008, pp. 23-24.

Elagib, N. (2009). “Assessment of Drought Across Central Sudan Using UNEP Dryness Ratio." Hydrological Research, Vol. 40, Issue 5, 481-494.

Ellis, J. E. and Swift, D. M. (1988). "Stability of African Pastoral Ecosystems: Alternate Paradigms and Implications for Development”. Journal of Range Management, Vol. 41, 450-459.

Elodie, et al. (2010). "The Household Food Insecurity Access Scale and an Index-Member Dietary Diversity Score Contribute Valid and Complementary Information on Household Food Insecurity in an Urban West-African Setting." The Journal of Nutrition 140 (12): 2233-40.

Food and Agricultural Organization (FAO). (2007). "Horn of Africa: Consultations on Food Security: Executive Summary of Country Reports for Discussion at a Multi-Country Consultation." Nairobi, June 25-26, (Rome: FAO, 2007).

Government of Kenya. (2004). Kenya Review and Appraisal Final Report on the Implementation of the Beijing Platform for Action, (Beijing+10), 1994-2004. Nairobi.

Gray, S. (2000). "A Memory of Loss: Ecological Politics, Local History, and the Evolution of Karimojong Violence.” Human Organization. Vol. 59, Issue 4, 401-18.

Ha-Joon, Chang. (2009). "Rethinking Public Policy in Agriculture: Lessons from History, Distant and Recent." Journal of Peasant Studies, Vol. 36, Issue 3, 477-515.

Hazell, Peter B. R., and Ulrich, Hess. (2010). "Drought Insurance for Agricultural Development and Food Security in Dryland Areas.” Food Security. Vol. 2, Issue 4, 395-405.

Heddinghaus, T.R. and Sabol, P. (1991). "A Review of the Palmer Drought Severity Index and Where do we Go from here? In: Proc. 7th Conf. On Applied Climatology, September 10-13,1991. American Meteorological Society, Boston, 242-246.

Held, et al. (2005). "Simulation of Sahel Drought in the 20th and 21st centuries." Proc. Nat. Acad. Sci. Vol. 102, 17891-17896.

Henriques, A. G. and Santos, M. J.J. (1999). "Regional Drought Distribution Model." Physics and Chemistry of the Earth, Part B: Hydrology, Oceans and Atmosphere, European Water Resources and Climate Change Processes." Vol. 24, Issue 1/2, 19-22.

Huber, Joseph. (2008). "The Global Diffusion of Environmental Innovations: The Standpoint of Ecological Modernization Theory." Global Environmental Change Vol. 18, 360-367. 
Journal of Global Strategic Management | V. 7 | N. 1 | 2013-June | isma.info | 140-153 | DOI: 10.20460/JGSM.2013715680 Hunt, Joseph M. (2005). "The Potential Impact of Reducing Global Malnutrition on Poverty Reduction and Economic Development." Asia Pacific Journal of Clinical Nutrition. Vol. 14, Issue S, $10-38$.

Joireman, Sandra, Fullerton. (1997). "Institutional Change in the Horn of Africa." UniversalPublishers, p. 1.

Jury, M. R. (2007). "Economic Impacts of Climate Variability in South Africa and Development of Resource Prediction Models.” Journal of Applied Meteorology. Vol. 41, Issue 1, 46-55.

Kaushik, P. D. and Nirvikar, Singh. (2004). "Information Technology and Broad-Based Development: Preliminary Lessons from North India.” World Development. Vol. 32, Issue 4, 591-607.

Keddy, P.A. (2007). "Plants and Vegetation: Origins, Processes, Consequences." Cambridge University Press, Cambridge, UK. p. 666.

Keen, David. (1994). The Benefits of Famine: A Political Economy of Famine and Relief in Southwestern Sudan, 1983-1989. New Jersey: Princeton University Press, 4.

Kwasi, Fosu Augustin. (2009). "Inequality and the Impact of Growth on Poverty: Comparative Evidence for Sub-Saharan Africa.” Journal of Development Studies. Vol. 45 Issue 5, 726-45.

Lewis, I. M. (1965). “The Modern History of Somaliland from Nation to State.” New York: Frederick A. Praeger, Publishers, p. 1.

Lotta, Themnér and Wallensteen, Peter. (2011). "Armed Conflict, 1946-2010." Journal of Peace Research, Vol. 48, Issue 4, 525-36.

Maxon, Robert, M. (1994). "East Africa: An Introductory History." Vol. 2, Revised edition, West Virginia University, p. 1

Nyakairu, F. (2011). "FAO Horn of Africa Drought: Drought Emergency.” 18 August 2011. From: http://www.fao.org/fileadmin/templates/tc/tce/pdf/FAO_ongoing_response_to_the_drought_in_the_H orn_of_Africa.pdf.

Özşahin, Mehtap, Zehir, Cemal, and Acar, Zafer. (2011), Linking Leadership Style To Firm Performance: The Mediating Effect Of The Learning Orientation, 7th International Strategic Management Conference, 30 June-2 July, 2011, Paris-France, Science Direct, Elsevier Procedia Social and Behavioral Sciences.

Prasad, PVV, and Staggenborg, S. A. (2008). "Impacts of Drought and/or Heat Stress on Physiological, Developmental, Growth, and Yield Processes of Crop plants.” In: Ajuha LR, Reddy VR, Saseendran SA, Yu Q (eds.). Response of Crops to limited Water: Understanding and Modeling Water Stress Effects on Plant Growth processes. American Society of Agronomy/Crop Science Society of America/Soil Science Society of America, Madison, WI, 301-356.

Quentin, Wodon and Zaman, Hassan. (2010). "Higher Food Prices in Sub-Saharan Africa: Poverty Impact and Policy Responses.” World Bank Research Observer. Vol. 25, Issue 1, 157-76.

Safra, Jacob, E. (2002). “The New Encyclopædia Britannica. Encyclopædia Britannica Inc, p. 61.

Schreck, C. J. and Semazzi, F. H. M. (2004). "Variability of the Recent Climate of Eastern Africa." International Journal of Climatology. Vol. 24, Issue 6, 681-701.

Shaohua, Chen and Ravallion, Martin. (2010). "The Developing World Is Poorer than We Thought, But No Less Successful in the Fight against Poverty." The Quarterly Journal of Economics, Vol. 125, Issue 4, 1577-1625.

Stock, Robert. (2004). "Africa South of the Sahara, Second Edition: A Geographical Interpretation." The Guilford Press, p. 26.

Şarlak, N. Kahya, E., and Bég, O. (2009). "Critical Drought Analysis: Case Study of Göksu River (Turkey) and North Atlantic Oscillation Influences.” J. Hydrol. Eng., Vol. 14, Issue 8, 795-802. 
Journal of Global Strategic Management | V. 7 | N. 1 | 2013-June | isma.info | 140-153 | DOI: 10.20460/JGSM.2013715680 Tilman, Brück and Schindler, Kati. (2009). "Smallholder Land Access in Post-War Northern Mozambique.” World Development." Vol. 37, Issue 8, 1379-89.

Touval, Saadia. (1997). "Somali Nationalism: International Politics and the Drive for Unity in the Horn of Africa." Cambridge, Mass.: Harvard University Press, p. 5.

UNHRC. (2005). "Refugees by the Numbers." 1 January-31 March 2005. Edition. From: http://www.unhcr .org/cgi- bin/texis/vtx/basics/opendoc.htm?tbl=BASICS\&id=3b028097c\#Refugees.

Wilhite, D.A. (2000). "Drought Planning and Risk Assessment: Status and Future Directions." Annals of Arid Zone. Vol. 39, Issue 3, 211-230.

Xinshen, Diao, Hazell, Peter, and Thurlow, James. (2010). "Role of Agriculture in African Development." World Development, Vol. 38, Issue 10, 1375-83.

Yillia, Paul T., Kreuzinger, Norbert, Mathooko, Jude M. (2008). "The Effect of In-Stream Activities on the Njoro River, Kenya. Part II: Microbial Water Quality." Physics and Chemistry of the Earth, Parts A/B/C. Vol. 33, 729-737.

Zehir, Cemal. (2005), The Activation Level of Crises and the Change of Strategic Targets of Enterprises in Turkey During the Depression Era, The Journal of American Academy of Business, Cambridge, Vol. 6, No. 1, March, 2005. 